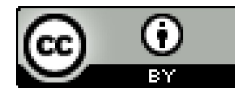

Esta obra está sob o direito de Licença Creative Commons Atribuição 4.0 Internacional.

\title{
O FATOR MOTIVAÇÃO NA GESTÃO DOS SERVIÇOS PÚBLICOS
}

\author{
Maria Betânia Costa Góes ${ }^{1}$
}

\section{RESUMO}

O fator motivação constituem implantar formas para conduzir pessoas em busca de benefícios tanto para si quanto para o grupo no qual esse membro está inserido. Pessoas desmotivadas e sem qualidade de vida no trabalho podem se tornar um problema para a organização. As instituições públicas atuais necessitam de pessoas capazes de trabalhar e facilitar a resolução de problemas em equipe, motivando os colaboradores e contribuindo para uma melhor produtividade. Desta forma, chega-se ao seguinte questionamento: Como deve-se influenciar o outro na motivação de uma equipe? Com o objetivo de mostrar competências e habilidades de como se motivar no trabalho que exerce. Para tanto, a metodologia utilizada foi a pesquisa bibliográfica, em fontes como: artigos publicados, livros de autores específicos. Inicialmente o trabalho apresentou a introdução ao assunto e os elementos necessários ao desenvolvimento do tema, em seguida o trabalho levantou um histórico do início da motivação, as características de uma melhor motivação após a qualidade no ambiente de trabalho melhorar. Na conclusão foram feitas considerações sobre o tema apresentado em estudo.

Palavras-chave: Motivação. Qualidade. Gestão. Equipe.

Submetido em dezembro de 2019 e aceito em janeiro de 2020.

\footnotetext{
${ }^{1}$ Possui graduação em Letras pela Universidade Federal de Alagoas.
} 


\section{INTRODUÇÃO}

As instituições públicas e privadas de um modo geral para terem sucesso neste século XXI, além de outros requisitos, têm que ter gestores que saibam lidar com pessoas, aproveitando, assim, a máxima produtividade desses indivíduos, fazendo com que eles tenham prazer no trabalho, e não que trabalhem somente por necessidade, efetuando assim só o necessário. Por isso é muito bom que administradores saibam como motivar. O conhecimento das forças motivacionais ajuda os administradores a compreenderem as atitudes de cada empregado no trabalho (NEWSTROM e DAVIS, 2015).

Levar motivação a colaboradores é tarefa muito difícil, pois uma mesma ação pode motivar uma pessoa e desmotivar outras. Às vezes, dando uma promoção a um funcionário, pode-se acabar com as ideias do companheiro de função, deixando um motivado e alegre, trabalhando com vontade, e outro com vontade de sair da empresa.

Cada pessoa se sente motivado de um jeito diferente, dependendo de como foi criado, do ambiente cultural em que vive e do jeito com que encara sua vida. Podemos perceber que algumas pessoas ficam satisfeitas com alguma coisa, para qual outra pessoa nem ligaria. Neste sentido cada um tem seu próprio sistema de valor.
Em vias normais, ou seja, as pessoas que não fogem à regra socialmente de buscar crescer financeiramente por meios escusos, sem exercer algum trabalho funcional. Sendo assim o ser humano busca através de seu trabalho, uma oportunidade de realizar as suas potencialidades, criando com isso uma indispensável ligação com a comunidade na qual vive. O trabalho só pode ser considerado como uma necessidade própria ao homem considerado apto socialmente correto, pois, é por meio dele, que se consegue reconhecer o próprio valor e, consequentemente, equilibrar expectativas e sentimentos de autoestima. $\mathrm{E}$, à medida que esse trabalho satisfaz às necessidades de autodesenvolvimento, a motivação fortifica-se cada vez mais.

Trata-se da estratégia mediante a qual a energia interior é reforçada e ampliada, permitindo que cada qual possa dar vazão aos apelos da sua motivação intrínseca.

O objetivo deste estudo é mostrar, a partir dos vários conceitos teóricos sobre motivação e liderança, a interrelação entre motivação e satisfação das pessoas no que se refere trabalhar no serviço público, bem como compreender seus principais aspectos. Como contribuição, espera-se que este estudo identifique numa situação de realidade, alguns motivos que expliquem por que as pessoas sentem-se mais ou 
menos satisfeitas em exercer sua profissão no serviço público.

A metodologia de pesquisa utilizada neste trabalho é de âmbito dissertativo fundamentada em pesquisas teóricas adquiridas através livros, revistas, jornais, artigos em sites específicos e os conhecimentos adquiridos de um modo geral ao longo do curso. Para que então desta forma possa-se ser observado à precisão e coerência das informações levantadas durante todo o trabalho.

Contudo, torna-se imprescindível que as Unidades de Ensino, reflitam sobre suas práticas e busquem novas abordagens de relacionar as diversas disciplinas com as

\section{METODOLOGIA}

A metodologia utilizada caracterizase como exploratória e descritiva, de cunho qualitativo, tendo como fonte o referencial bibliográfico de libros obtidos em bibliotecas físicas e virtuais.

\section{RESULTADOS E DISCUSSÕES}

\section{Origem}

A década de cinquenta foi um período fértil para o desenvolvimento de conceitos de motivação. Três teorias foram formuladas nesse período, as teorias $\mathrm{X}$ e $\mathrm{Y}$, a Hierarquia das Necessidades, e a teoria da Motivação-Manutenção. As teorias X e Y, de Douglas McGregor, representam reais necessidades dos educandos, considerando assim, a interdisciplinaridade como prática mediadora para construção de conhecimentos significativos.

Os educandos por sua vez, almejam, sobretudo, ver sentido nos conteúdos trabalhados pelos docentes nas diversas disciplinas e as suas autênticas necessidades pessoais e no convívio com os seus semelhantes. Há, pois, habilidades e competências que podem ser muito bem desenvolvidas pelas escolas, desde que tenham compromisso com a aprendizagem e desenvolvimento pleno de seus educandos e buscam cumprir seu papel efetivamente.

As categorias temáticas criadas a partir da leitura minuciosa do material selecionado foram: origem, importância e significado da motivação, conceitos e técnicas para a melhoria na prestação dos serviços e a motivação do servidor público no ambiente de trabalho.

dois conjuntos de hipóteses extremadas e irreais sobre a natureza do homem: uma basicamente negativa, denominada teoria $\mathrm{X}$ e outra basicamente positiva, denominada teoria $\mathrm{Y}$.

Maslow (2012, p.56), na sua teoria da hierarquia das necessidades, afirma que existem cinco necessidades que deixam de motivar quando substancialmente satisfeitas. Herzberg propôs uma teoria 
Bifatorial de motivação-manutenção. Maslow (2012) se preocupava com as fontes de motivação no sentido da vida em geral, enquanto Herzberg focalizou as fontes de motivação que pareciam estar relacionadas ao trabalho e às realizações no trabalho.

McClelland conduziu pesquisas relativas à necessidade de realização. Afirma que as pessoas com alto nível de auto realização, têm necessidade compulsória de sucesso e tendem ao auto desempenho. A maior parte das teorias atuais que consideram a motivação como uma predisposição interior para a ação, tem suas raízes nos conceitos que priorizam as necessidades como fontes de energia, capazes de dinamizar o comportamento motivacional.

Tais enfoques estão mais preocupados em descobrir as origens das forças motivacionais, o que significa conhecer especialmente de que maneira os seres vivos se comportam. Aquilo que mais importa, a partir daí, é desvendar como se dá a psicodinâmica da motivação. Antes da chamada revolução industrial, ninguém se preocupava com os problemas da motivação das pessoas. As unidades de produção eram pequenas e as técnicas de produção muito simples. O dia de trabalho era longo, mas não havia problemas acerca da utilização dos esforços humanos e da motivação.

Quando a indústria cresceu, com o aumento de capitais, fábricas, maquinários, começou a visar um aumento de produtividade. $\mathrm{O}$ trabalhador passou a ser um outro elemento do processo de produção. E acreditou-se que o melhor incentivo seria o dinheiro. $\mathrm{O}$ colaborador era estandardizado numa administração científica.

O pai da ideia foi Taylor. "Todas as pessoas são iguais, e a administração científica vai aumentar a satisfação do trabalhador" concepção Tayloriana. O colaborador começou a ser pago em função da produção, com salários adicionais. No entanto, perceberam as pessoas, que não podiam produzir além de certo nível, pois não podiam exceder as demandas do mercado, já que seriam despedidos. Entrou em jogo a necessidade de segurança (HERZBERG, 2012)

As reais causas da motivação humana iniciaram, e então a administração científica começou a ter enormes prejuízos. Aparecendo finalmente Elton Mayo, denominado para resolução de fracassos em uma organização. Realizou assim, Mayo, uma série de experiências, reconhecendo que as pessoas buscavam mais do que dinheiro no trabalho e necessitavam de outros estímulos. Verificou que eles 
desejavam pertencer a um grupo, e serem considerados como membros significativos do mesmo.

$\mathrm{Na}$ proporção que os trabalhadores passaram a obter um melhor êxito no exercer do seu trabalho diário passou então a existir um sentimento maior do seu valor pessoal principalmente quando começam a participarem das decisões internas que possam melhorar o desempenho no seu ambiente de trabalho. E, ainda se pode destacar, que o fator motivação é crescente quando existem incentivos e estavam sendo inclusos, como: segurança, afiliação, estima, interesse pelo trabalho e êxito. $\mathrm{O}$ grande administrador Mayo, iniciou assim, o movimento de relações humanas.

Neste sentido, os exemplos dos trabalhos exercidos e publicados de Mayo, passou a servir para mostrar que a produtividade aumenta consideravelmente quando os trabalhadores conseguem, através de experiências adquiridas, um sentimento maior de valor pessoal: participando nas decisões que afetavam o seu trabalho, ter um envolvimento no próprio trabalho, sentir-se mais seguros em seu trabalho, devido ao tratamento permissivo e amistoso do experimentador, ter a oportunidade de ganhar mais dinheiro, devido ao sistema de recompensa como incentivo ao grupo.
Alguns pesquisadores, como Maccoby (2013, p.49), por exemplo, assinalam que o trabalho representa o referencial que reata o homem ao mundo da realidade e assim fornece os indícios necessários que se precisa, para conhecer as expectativas, as ideias e as visões pessoais que fazem sentido para cada um.

Isso, sem dúvida, ajuda também a disciplinar talentos, bem como facilita redirecionar aqueles impulsos que já fazem parte das características de cada um. Só então há condições de delinear com mais clareza o conceito de motivação como aquilo que liga o desejo natural das pessoas de se engajarem em atividades de trabalho, mas agora fazem pelo prazer que elas proporcionam, tendo em vista a satisfação interior que podem oferecer.

Maslow (2012, p. 54), tomando por base as suas observações como psicólogo clínico, percebe que duas premissas são importantes a respeito do comportamento motivacional. Inicialmente, propõe que as pessoas assumam o papel de portadoras de desejos, estando principalmente motivadas em procurar satisfazer a tipos específicos de necessidades.

Para ele, quando essas necessidades não podem ser satisfeitas, o indivíduo é interiormente invadido por um estado de tensão que procura reduzir a todo custo. Quando não é possível encontrar aquele 
fator que reduz tal tensão interna, as necessidades não satisfeitas não desaparecem, continuam representando estados interiores inoportunos, indesejáveis e desagradáveis, o que aumenta a necessidade de se livrar dela como único meio de baixar os níveis praticamente insuperáveis de ansiedade.

Para melhor manejar o conceito de motivação, um bom ponto de partida é ligálo ao sentido que as pessoas dão ao seu trabalho. Torna-se particularmente difícil, senão até mesmo impossível, experimentar qualquer tipo de satisfação motivacional quando se está ligado a um trabalho que não tem ou não faz o menor sentido. As empresas querem funcionários motivados, mas não sabem como motivá-los. De um lado, porque ainda não se sabe distinguir entre o que é causa e o que é efeito no comportamento motivado.

E, também, não se descobriu, se o comportamento é causado por fatores intrínsecos ou extrínsecos ao indivíduo ou ao grupo. As diferenças entre as pessoas dificultam enormemente a definição de parâmetros universais que as empresas possam utilizar para motivar as pessoas em igualdade de condições.

Há sempre um componente subjetivo na motivação que provoca uma enorme complicação. A motivação funciona como um dinamizador, um impulsionador do comportamento humano. Muitos gerentes rotulam como preguiçosos empregados que parecem não ter motivação.

Lévy-Leboyer (2014, p.54) propõe que, de alguma forma, as pessoas precisam do trabalho, uma vez que ele atende a necessidades econômicas no sentido de se adquirir o necessário para a sobrevivência; as necessidades sociais de se pertencer a um grupo e àquelas necessidades que buscam auto realização.

Os empregados estão à busca de cargos que tenham algum significado e permitam a sua própria auto realização. Trabalhar, produzir, contribuir para o progresso ao fazer uma obra útil, representa uma afirmação da própria liberdade e identidade. É esse trabalho que situa o indivíduo na sociedade, sendo que pelas experiências de vida ativa são construídas a identidade e a personalidade de cada um.

Quando o trabalho se transforma em uma atividade secundária ou fonte de malestar, uma parte do esqueleto social é fragmentada e a dinâmica tradicional do desenvolvimento da personalidade é colocada em dúvida. Em situação de trabalho, as pessoas querem ser respeitadas enquanto indivíduos, bem como valorizam o reconhecimento por suas realizações, lealdade e dedicação. 
Dentro de uma perspectiva mais abrangente, os modelos de administração consideram os trabalhadores como indivíduos que se mostram motivados por um conjunto mais complexo de fatores, que, por sua vez, guardam correlações entre si. Além disso, começa-se a admitir, como ponto de partida, as restrições impostas pelas diferenças individuais em situação de trabalho.

\section{Importância e significado da motivação}

Glasser (2012, p.15) propõe que, o fracasso da maioria de nossas empresas não está na falta de conhecimento técnico. E, sim, na maneira de lidar com as pessoas. Foge à nossa compreensão o hábito dos administradores de achar que os trabalhadores não produzem com qualidade, apenas por falta de conhecimento técnico. $\mathrm{Na}$ realidade, isso está ocorrendo devido à maneira como são tratados pela direção das empresas.

O problema do comportamento humano nas organizações sempre existiu; contudo, somente no momento em que as empresas já não precisam se preocupar tanto com dificuldades tecnológicas, por causa das máquinas inteligentes, tampouco com os recursos financeiros devido a uma economia relativamente estável, é que se reconhece que o sucesso esperado não tem sido possível atingir.
Se a tecnologia já não é problema, se a inflação está relativamente controlada, tudo deveria ser melhor e não está sendo. É assim que as pessoas estão agora ganhando lugar de destaque, pois o relativo fracasso só pode estar ocorrendo porque provavelmente elas sejam o principal problema. Com essa tendência de revalorização, muito se tem pesquisado e escrito sobre o tema da motivação. Essas novas propostas têm claramente inundado não somente as teorias organizacionais, como também as práticas de gestão em administração de maneira geral (LATHAN, 2015).

Por mais que se tenha conseguido aperfeiçoar as técnicas e os procedimentos de escolha, desenvolvimento e compensação das pessoas no trabalho pela gerência de recursos humanos, as empresas parecem continuar enfrentando os mesmos e antigos problemas. Isso permite suspeitar que as dificuldades não tenham, neste caso, sido originadas simplesmente pela qualidade das técnicas utilizadas nas diferentes áreas especializadas em gerir pessoas. As raízes desses problemas são mais profundas do que se possa imaginar e estão menos evidentes do que se gostaria de desejar.

A diversidade de interesses percebida entre os indivíduos permite aceitar, de forma razoavelmente clara, que 
as pessoas não fazem as mesmas coisas pelas mesmas razões. É dentro dessa diversidade que se encontra a principal fonte de informações a respeito do comportamento motivacional, por paradoxal que isso possa parecer. Quando se fala de motivação humana, parece inapropriado que uma simples regra geral seja considerada como recurso suficiente do qual se lança mão quando o objetivo é a busca de uma explicação ao mesmo tempo mais abrangente e mais precisa sobre as possíveis razões que levam as pessoas a agir (LEVY LEBOYER, 2014).

\section{Conceitos e técnicas para a melhoria na prestação dos serviços}

Da mesma forma que o objetivo de melhoria, o envolvimento das pessoas em todas as fases da prestação dos serviços é fundamental. Quanto mais preparados os funcionários para enfrentar problemas referentes à qualidade na prestação dos serviços, melhores níveis de produtividade serão obtidos.

O processo inicia-se com a
identificação das necessidades expectativas do cliente, manifestas nas dimensões do serviço. Com base nestas dimensões, a empresa pode identificar seus projetos críticos-chave e adequá-los às necessidades dos seus clientes (LUDWIG, 2011, p.43).
Para uma melhoria do atendimento ao cliente na prestação dos serviços, é necessário estabelecer prioridades por meio dos processos que aumentam imediatamente a satisfação do cliente com o serviço prestado. A definição das prioridades no processo de melhoria consiste em identificar tarefas, procedimentos (atividades) ou sistemas, fundamentais para a qualidade dos serviços.

A seguir, são apresentadas ferramentas e técnicas que podem ser utilizadas para determinar as dimensões e requisitos dos serviços. Estas ferramentas ou técnicas de gestão da qualidade podem ser utilizadas na identificação das causas significativas de alguns efeitos não desejados. Entre estas técnicas para a melhoria da prestação de serviços, pode-se citar (LUDWIG, 2011, p.43):

- Gestão da Qualidade Total (TQM);

- Os Círculos de Controle da Qualidade (CCQ);

- O Desdobramento da Função Qualidade (QFD);

- O ciclo Plan-Do-Check-Act (PDCA)

Estas técnicas e ferramentas são úteis para analisar a melhoria do atendimento ao cliente durante a prestação de um serviço, visando a sua satisfação final. 
A motivação do servidor público no ambiente de trabalho

$\mathrm{Na}$ atual conjuntura, uma das buscas essenciais do ser humano é a qualidade de vida, pois, estar em equilíbrio sócio econômico, familiar e é claro, consigo mesmo é estar de bem com seus afetos e emoções, pois por mais difícil que seja lidarmos com esses sentimentos, não podemos fugir deles, entretanto a todo momento estamos mantendo contato com outras pessoas tendo em vista que o surgimento de afetos e emoções é algo bastante natural nas relações humanas.

Para se obter uma qualidade de vida estável é necessário aliar uma série de fatores que darão sustentação ao bom funcionamento biopsicossocial e espiritual da pessoa humana, onde esses fatores seriam: reconhecimento, condição financeira estável, nível de estresse aceitável, boa alimentação, lazer, afetos e emoções entre outros, tendo em vista que no trabalho não se dá diferentemente, mas, os afetos e as emoções são os pilares que norteiam essa tão almejada qualidade de vida.

Segundo Zanelli, et. al. (2014, p. 207): "poucos de nós não compartilham a crença de que as emoções, e especialmente os afetos dão uma tonalidade especial a existência humana e devem exercer um papel importante na sobrevivência da espécie, na construção histórica, no ajustamento social e no desenvolvimento da pessoa."

Desta forma, fica explícito que a maioria das pessoas concordam que as emoções, e especialmente os afetos dão um colorido extremamente significante a existência do homem, apontando o importante papel exercido por estes, dessa forma, o fenômeno trabalho também opera embasando-se nesses dois aspectos para alicerçar a condição individual e coletiva na qualidade de vida dos trabalhadores que estão inseridos no mercado de trabalho.

Ressaltando esses aspectos no mercado informal, é claro e notório que essas relações se estabelecem de forma mais natural entre os indivíduos que o compõem, tendo em vista que os laços de afeto semeados nesse meio é demonstrado por exaltação emocional em muitos dos casos, pois quando um companheiro de trabalho é perseguido, nesse instante sem adentrar no mérito, se essa perseguição é justa ou injusta, pelo sistema, nota-se que os trabalhadores se protegem, tentando preservar-se individualmente e preservando também o seu conviva de trabalho.

Vivenciando diariamente essas situações, e desamparados pelo poder público, estes trabalhadores em sua maioria não conseguem obter uma qualidade de vida digna, pois estão suscetíveis a uma 
infinidade de moléstias e mazelas que circundam o seu dia a dia e consequentemente de seus familiares.

Dentre vários fatores que contribuem para fortalecer o vínculo do indivíduo com o trabalho, pode-se descrever os fatores: satisfação, envolvimento e comprometimento são vínculos que tendem a apresentar níveis significativos de correlação positiva entre si.

Assim sendo, o indivíduo que se apresenta mais satisfeito, envolvido e comprometido com o seu trabalho, demonstra maior vínculo com sua arte laboral. Dessa forma, uma condição de trabalho que não possibilite que o

\section{CONSIDERAÇÕES FINAIS}

Embora o comportamento motivacional implique uma ação por parte do indivíduo, ele está ligado a estruturas estáveis de sua personalidade. Como a personalidade, então, as características motivacionais permanecem de alguma forma estáveis ao longo dos anos. É dessa forma que o Estilo de Comportamento Motivacional pode ser entendido como um perfil estrutural básico ou como uma espécie de modelo interior.

As pessoas trazem, dentro de si mesmas, seus potenciais motivacionais que são as suas necessidades, as suas pulsões e trabalhador vivencie as relações acima descritas, dificilmente conseguirá manter um vínculo verdadeiramente forte com o seu trabalho.

Contudo, as relações estabelecidas entre professor e aluno precisam ser consideradas e definidas. Cada um no seu papel, pois, "é necessário saber quem é quem, porém, com respeito, a mutualidade, a reciprocidade são indicadores de alteridade que precisam ser preservados". (FAZENDA, 2013). Considerando ainda, nessas relações alguns dos pontos relevantes no processo de ensino e aprendizagem, em sala de aula, como a subjetividade e a objetividade pretendida pela instituição.

seus desejos. A forma pela qual esse conjunto é atendido determina maiores ou menores níveis de satisfação motivacional. É por isso que medidas administrativas de caráter genérico e impessoal podem ser consideradas como altamente desmotivantes.

Da mesma forma, as organizações devem considerar que são impotentes para motivar quem quer que seja, pois, as pessoas já estão motivadas ao serem portadoras de necessidades próprias. Elas só podem oferecer a oportunidade para que as forças motivacionais entrem em ação. Parece ser um paradoxo o fato de não se conseguir motivar quem quer que seja, ao 
mesmo tempo em se consegue ser capaz de desmotivar os outros pelo não-atendimento da sua diferença individual de Estilo Motivacional.

São as necessidades e não aquilo que satisfaz essas necessidades a fonte da sinergia motivacional. Cada pessoa tem um conjunto de necessidades estruturadas de maneira particular, dando, portanto, valor e sentido diferentes aos fatores de satisfação. Em situação de trabalho, por exemplo, só valorizará novos desafios quem estiver incomodado com a rotina de atividades repetitivas e desinteressantes; só valorizará o relacionamento harmônico com os colegas, aqueles que se sintam realmente mal por estarem privados de uma convivência agradável, e assim por diante.

Não somente a análise dos dados obtidos através da pesquisa, como, também, numerosas teorias mostram que, do ponto de vista da interação do indivíduo com o seu ambiente profissional, o enfoque mais adequado difere daquele, tradicionalmente, adotado.

Sabe-se, atualmente, que as pessoas podem ter todos os tipos de necessidades interiores e tender para os mais variados objetivos sem que seja necessário estabelecer uma prioridade hierárquica entre tais objetivos, como o apresentado por muitos trabalhos que se utilizam da teoria de Maslow. Assim sendo, a possível solução para um melhor conhecimento da motivação não será organizar as pessoas em função dos conjuntos de objetivos motivacionais parecidos, mas descobrir a maneira pela qual cada um perseguir diferentes caminhos para chegar a um mesmo objetivo.

O ser humano, quando elabora para si mesmo uma estratégia comportamental, escolhe um caminho que seja o mais natural ao seu tipo de preferência motivacional. Considerando que todas as pessoas possuem, ao mesmo tempo, as quatro orientações de Comportamento Motivacional (participação, ação, manutenção e conciliação), aquilo que vai diferenciar uma da outra é a ênfase que cada uma mostra em termos dessas diferentes preferências.

São os orientadores mais, frequentemente, utilizados, ou melhor, o primeiro estilo, aquele que dirigirá especialmente o processo de orientação perceptiva na busca dos esquemas produtores ou fatores de satisfação existentes interna ou externamente aos indivíduos.

Do ponto vista da motivação intrínseca, as pessoas são vistas como possuidoras de necessidades que lhes são próprias, e as leva a tirarem o melhor partido que podem daquilo que já possuem, isto é, seus conhecimentos, habilidades e 
experiências acumuladas. Cada um é visto como impelido para o aproveitamento do seu potencial interior. As habilidades intelectuais e os potenciais de emoções desempenham importante papel nesse contexto. Isto configura aquilo que alguns autores denominam de auto realização.

A escola, portanto, deverá rever suas teorias e práticas, como a possível interdisciplinaridade que poderá ser desenvolvida no cotidiano escolar.

\section{REFERÊNCIAS}

GLASSER, W. Administração de liderança. São Paulo: Editora Best Seller, 2012

HERZBERG, F. O conceito de higiene como motivação e os problemas do potencial humano no trabalho. In: HAMPTON, D. R. Conceitos de comportamento na administração. São Paulo: EPU, 2012

LEVY-LEBOYER, C. A Crise Das Motivações. São Paulo, 2014.

LOCKE, E. A.; LATHAN, G. P. A theory of goal-setting and task performance. Englewood Cliffs, NJ: Prentice Hall, 2015.
Buscando, assim, chegar a uma educação que favoreça a construção de conhecimentos efetivos, partindo dos princípios e valores, como: o respeito ao conhecimento do outro, a cooperação, o diálogo constante, na busca de preparar pessoas para atuar criticamente no meio em que se estão inseridas e que almejam a proficiência a partir de um novo agir socialmente para o bem de todos.

LUDWIG, A. Customer Relationship Management - CRM. Disponível no site: www.fearp.usp.br/egna/resumos/ludwig.pd f. 2011 Acesso realizado em maio de 2019.

MACCOBY, M. Travailler, pourquoi? Une nouvelle théorie de la motivation. Paris: Inter Editions, 2013.

MASLOW, A. H. A Theory of Human Motivation. 1943.et.al 2012 Disponível http://psychclassics.yorku.ca/Maslow/moti vation.htm. Acesso em maio de 2019.

ZANELLI, J. C.; Bastos, A. V. B. Inserção profissional do psicólogo em organizações e no trabalho. In: J. C. Zanelli, J. E. Borges-Andrade, \& A. V. B. Bastos (Orgs.), Psicologia, Organizações e Trabalho no Brasil Porto Alegre: Artmed, 2014. 